\title{
THREE-DIMENSIONAL SENSORY AND MOTOR SPACE: POLYSENSORY INTERACTION IN THE GENERATION OF EYE MOVEMENTS
}

\author{
Giens, France, September 5-10, 1997 \\ Co-Chairmen: Volker Henn (Zurich) and Maarten Frens (Rotterdam) \\ Vice-Chairman: Werner Graf (Paris)
}

This series of meetings concerns the progress in the field of spatial coding, especially as it refers to our sense of motion and orientation and as it leads to specific voluntary or reflex motor responses such as eye movements. Specific topics of this meeting include: Local problems of sensorito-motor transformations; neurophysical mechanisms of fusion of sensors; laws of eye movement; and sensory substitution and prosthesis.

The conference is open to researchers worldwide, whether from industry or academia. Participation will be limited to 100 . The emphasis will be on discussion about new developments. Poster sessions will be organized. The registra- tion fee covers full board and lodging. Grants will be available for younger scientists, in particular those from less favoured regions in Europe.

For information and application forms, please contact:

Dr. Josip Hendekovic

European Science Foundation

1 quai Lezay-Marnésia

67080 Strasbourg Cedex, France

Tel: +33-3-88-76-71-35

Fax: +33-3-88-36-69-87

E-mail: euresco@esf.org

On-line information: http://www.esf.org/euresco 